3. Thomas HN, Hess R, Thurston R. Correlates of sexual activity and satisfaction in midlife and older women. Ann Fam Med. 2015;13(4): 331-337.

4. Sussman AL, Helitzer D, Bennett A, Solares A, Lanoue M, Getrich CM. Catching up with the HPV vaccine: challenges and opportunities in primary care. Ann Fam Med. 2015;13(4):354-360.

5. Steele LS, Macdonald EM, Gomes T, et al. Rates of anomalous bupropion prescriptions in Ontario, Canada. Ann Fam Med. 2015;13(4): 343-346.

6. DeVoe JE, Marino M, Gold R, et al. Community health center use after Oregon's randomized Medicaid experiment. Ann Fam Med. 2015;13(4):312-320.

7. Ryan AM, Shortell SM, Ramsay PP, Casalino LP. Salary and quality compensation for physician practices participating in accountable care organizations. Ann Fam Med. 2015;13(4):321-324.

8. Tipirneni R, Vickery KD, Ehlinger EP. Accountable communities for health: moving from providing accountable care to creating health. Ann Fam Med. 2015;13(4):367-369.
9. Stange KC. Possible unintended consequence of an evidence-based clinical policy change. Ann Fam Med. 2015;13(4):iii.

10. Ursu A, Sen A, Ruffin MT. Impact of cervical cancer screening guidelines on screening for chlamydia. Ann Fam Med. 2015;13(4): 361-363.

11. Brown EJ, Kangovi S, Sha C, et al. Exploring the patient and staff experience with the process of primary care. Ann Fam Med. 2015; 13(4):347-353.

12. Pols DHJ, Bramer WM, Bindels PJE, van de Laar FA, Bohnen AM. Development and validation of search filters to identify articles on family medicine in online medical databases. Ann Fam Med. 2015; 13(4):364-366.

13. Goldstein AO. Affordable care? Ann Fam Med. 2015;13(4):370-372.

14. Selwyn PA. Openings. Ann Fam Med. 2015;13(4):381-383.

15. David SP, Johnson SG, Berger AC, et al. Making personalized health care even more personalized: insights from activities of the IOM genomics roundtable. Ann Fam Med. 2015;13(4):373-380.

\title{
EDITORIAL
}

\section{Perspectives in Primary Care: The Foundational and Urgent Importance of a Shared Primary Care Data Model}

\author{
Larry A. Green, $M D^{1}$ \\ Michael Klinkman, $M D, M S^{2}$ \\ 'Department of Family Medicine, University of Colorado, Denver, Colorado \\ ${ }^{2}$ Department of Family Medicine, University of Michigan, Ann Arbor, Michigan \\ Ann Fam Med 2015;13:303-311. doi: 10.1370/afm.1817.
}

$\mathrm{T}$ he purpose of this commentary is to inspire a coordinated effort by primary care leaders, communities, and health information technology (IT) experts to establish a conceptual primary care data model. A shared data model is necessary to guide the development of health IT standards that will enable primary care clinicians to make essential, foundational contributions within redesigned systems of care, education, and research. This work requires that we understand the core functions of primary care in a transformed US health care system.

Primary care provides integrated, accessible health care by clinicians who are accountable for addressing most personal health care needs, developing a sustained partnership with patients, and practicing in the context of family and community. ${ }^{1}$ The role of primary care is complex, with well-defined attributes that can serve as the foundation of health care delivery systems. As a service, primary care can be expected to improve individual and population health, the quality of health care, and the efficiency and affordability of health care, as well as relieve inequities in health and health care. ${ }^{2-4} \mathrm{~A}$ jurisdiction with weak primary care would be expected to have comparatively worse health and health care, be unnecessarily expensive, and result in substantial disparities in health and health care within its population-as is the case for the United States. ${ }^{5,6}$

All problems concerning health and health care may exist in primary care and are accepted and managed in partnerships with individuals, families, com-

Conflicts of interest: author reports none.

\section{CORRESPONDING AUTHOR}

Michael S. Klinkman, MD, MS

Department of Family Medicine

University of Michigan Health System

1018 Fuller Street

Ann Arbor, MI 48103-1213

mklinkma@umich.edu 
munities, and other health and health care enterprises. Thus, primary care probably represents health care's most complex information challenge. There is not yet a shared understanding of what particular data, from which diverse sources, should be collected, organized, linked, and used to enable excellent primary care.

Developing a data model for primary care requires examining both its historical and contemporary contexts. Throughout the 20th century, the elaboration of disciplines, specialties, and sectors concerned with health and health care ${ }^{7}$ has yielded well-intentioned efforts to advance health care and improve health that are important but fragmented and not well-integrated, characterized as "silos of understanding that misrepresent the world in ways that block advancement." ${ }^{8}$ Yet, even as dramatic changes in the science base, organization, delivery, and financing of health care occurred during the last century, frontline primary care practices have persisted and remained stable as the largest platform of formal health care delivery in the United States. ${ }^{9,10}$ Much that is known about what is necessary to achieve high-performing primary care ${ }^{1,8,11}$ has exposed the need for modernized robust care capable of providing safe, comprehensive, prioritized, and personalized care to resolve most of the health concerns most people have most of the time.

Primary care clinicians-filled at once with high hopes and considerable fear and frustration-continue to struggle to establish their place, integrative role, knowledge base, and ways of working with patients, families, and communities ${ }^{12}$ in an environment shaking with concern, complexity, and change. The financial unsustainability ${ }^{13}$ and persistent quality and performance gaps of the US health care enterprise ${ }^{5,6}$ have inspired recent efforts to reimagine and reconstruct our approach to health and health care delivery. Nations have rediscovered that health is a community affair, ${ }^{14,15}$ that physical and mental health are inseparable, and that prevention of mental, emotional, and behavioral problems has been neglected. ${ }^{16,17}$ There are renewed calls for exploring how to integrate primary care and public health. ${ }^{18}$ The idea of a learning health care system, capable of closing the research-practice gap by deriving and applying evidence from everyday clinical practice, has matured. ${ }^{19}$ The importance and methods of community engagement in the discovery and application of knowledge for health and health care improvement has been established. ${ }^{20}$ The information revolution's transformative power has penetrated health care, ${ }^{21,22}$ and there is progress toward counting what counts, measuring what matters, and generating a parsimonious set of core measures to guide improvements in care and relieve the processes that burden health care without sufficient return on investment. ${ }^{23}$
These developments provide a tremendous opportunity to re-engineer primary care.

There are good reasons to think that establishing a conceptual data model for primary care is important and achievable now. In 2002 the United States National Committee on Vital and Health Statistics (NCVHS) published a vision for population health statistics in the 21 st century. ${ }^{24}$ Figure 1 displays its proposed reference set of community attributes and contextual cultural, political, and natural environmental factors that influence population health.

Communities across the country want data about health and health care that is actionable at local levels, but they lack the needed infrastructure to enable stewardship of relevant, personalized, and protected data for health and health care improvement. Authoritative recommendations for moving forward using data for continuous learning in health and health care have been formulated regarding data sources and mapping, public and patient engagement, building a clinical data learning utility, and governance. ${ }^{25}$ The hopes, fears, enablers, and impediments that accompany transforming communities to learning systems for health in the information age are being exposed. ${ }^{25,26}$ The Office of the National Coordinator for Health Information Technology (ONC), at the forefront of federal health IT efforts, is promoting nationwide health information and exchange to improve health and care. Its 10-year vision $^{27}$ identifies 5 essential building blocks, including core technical standards and functions, and envisions:

By 2024, individuals, care providers, communities, and researchers should have an array of interoperable health IT products and services that allow the health care system to continuously learn and advance the goal of improved health care. This "learning health system" should also enable lower health care costs, improved population health, truly empower consumers, and drive innovation.

Circle Square, Inc, closely observing trends in health IT, reported in June of 2014 that " $40 \%$ of health systems are indifferent or dissatisfied with their electronic health records (EHRs) with health IT being a top driver of costs in health systems.... Patientcentered medical home model gets results ...EHRs are not enough." Health IT is attracting billions of dollars of venture capital. ${ }^{28}$ The member boards of the American Board of Medical Specialties have adopted standards for physician certification that move beyond taking tests to using data to improve practice. ${ }^{29}$ Yet there is great frustration with health IT at the clinical practice level. Major investment in adopting EHR systems has not led to gains in clinical productivity or personal or community health benefits. ${ }^{30}$

Clearly, a journey is underway toward health IT and 


\section{Figure 1. Proposed NCVHS community-population health data model.}

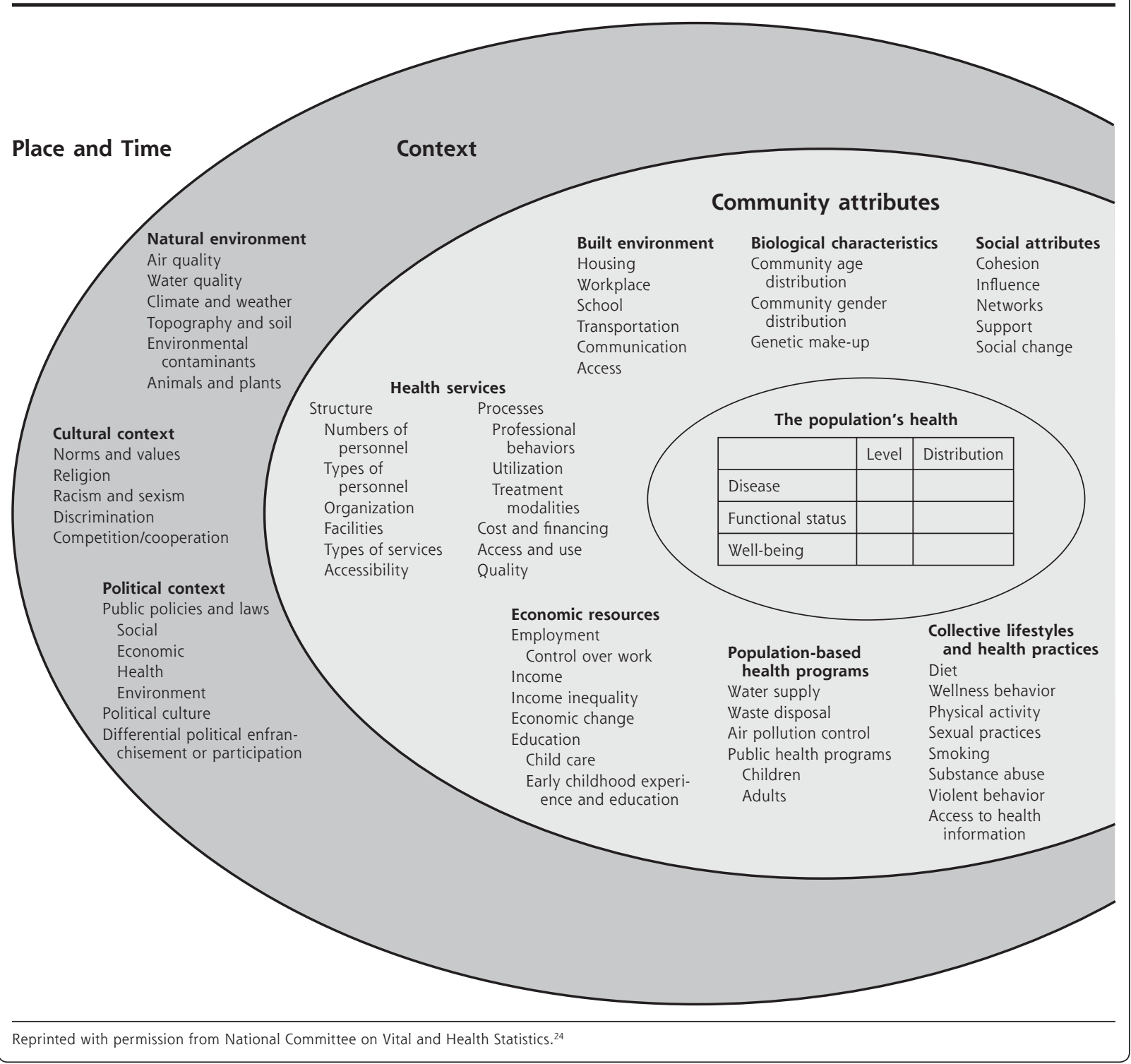

use that catapults clinicians, scientists, people, health care systems, and communities into fruitful partnerships to discover the origins of disease and illness, promote well-being, and relieve suffering. It is difficult to imagine a sufficient data infrastructure that does not enable primary care, and it seems sensible that leaders in family medicine and primary care should provide guidance about the data requirements of modernized primary care. The first critical step in this process would be to develop, sanction, and share with health IT developers and other decision makers a proper data model to support robust primary care. Fortunately, there are reasons to think that new technologies may be able to overcome the massive primary care data challenges, and there is prior work from which to build. ${ }^{31}$

\section{A CONCEPTUAL DATA MODEL FOR PRIMARY CARE}

\section{What is a Data Model?}

A data model is a set of objects, relationships, and rules that describes essential data elements and standardizes how they relate to each other in ways that foster understanding and enable helpful action. ${ }^{32,33}$ A relevant data model can provide a concise representation of reality in a way that ensures communication between people or actors in a system.

\section{Why Do We Need a Primary Care Data Model?}

- To guide the parsimonious collection of data that can accurately describe the essential core content of the primary care domain 
- To specify the data relationships necessary to capture the clinical processes of primary care

- To improve the design of clinical information systems that support the everyday clinical practice of person-centered primary care

- To enable and accurately assess primary care for individuals, families, and communities within the larger health care enterprise

Our current health IT infrastructure best serves the few individuals who receive care for known diseases in hospitals within integrated health systems. EHR systems are primarily designed to provide standardized clinical documentation to support disease-based care and meet complex billing requirements. Many systems can now provide embedded clinical decision support and standardized clinical pathways for chronic diseases.

But for most individuals in our communities who experience symptoms and decide to seek care, there is no common machine language to describe those symptoms, their impact, the reasons for seeking care, or the personal and social context in which care is provided. There is no common machine language to describe and capture individuals' goals or their priorities for health or healing. And there is no common machine language to capture the larger community context envisioned by the NCVHS. It is not surprising that health IT systems are poorly designed to support primary $\operatorname{care}^{34,35}$; developers have been given very little to work with.

We need to provide health IT developers with a sufficient primary care data model-linked to the NCVHS community model-that describes, structures, and standardizes this content to support the higherorder primary care functions of integrating, personalizing, and prioritizing care to foster healing and health. ${ }^{35}$

\section{What Has Been Done?}

Much work has been done recently to revise existing classification and terminology tools to support primary care. The World Health Organization (WHO) is nearing completion of the International Classification of Diseases, Eleventh Revision (ICD-11). The International Health Terminology Standards Development Organization (IHTSDO) is preparing to release the Systematized Nomenclature of Medicine-Clinical Terms (SNOMED CT) Primary Care Reference Set. The World Family Medicine Organization (Wonca) International Classification Committee has revised the International Classification of Primary Care-2 (ICPC-2), mapped it to ICD and SNOMED-CT, and is beginning work on ICPC-3. These efforts have all been limited by the absence of a guiding data model. The Comité Européen de Normalisation Technical Committee 251 published a detailed primary care information model ${ }^{36}$ and an expert group chartered by the Robert Graham Center in the United States developed a draft data model in $2007,{ }^{37}$ but neither model gained wide acceptance, likely lost in the wake of the large-scale events described above.

\section{A New Starting Point?}

Figure 2 displays an updated version of the 2007

Robert Graham Center's primary care data model, along with its key operational components (inputs and outputs).

This high-level model is built around 5 core objects: Persons, Problems, Goals, Clinical Modifiers, and Actions. Each object is composed of several data elements.

Persons includes essential demographic and biopsychosocial data elements related to the person experiencing care, capturing trait data expected to be stable with time. Biologic data could include a genetic profile identifying disease risks in addition to current data, such as medication allergies; psychological data could identify internal emotional structures related to selfconcept, identity, and autonomy that shape a person's response to illness; and social and demographic data would identify and capture important social determinants of health.

Problems includes the health and social problems currently known to and addressed by the clinical team providing care, linked where possible to the actions taken over time to address the problem. This concept is similar to the problem list in current practice, with 2 important distinctions: it includes active social problems, and it does not include previously experienced but now inactive clinical events or problems (included in this model as Clinical Modifiers) or risk factors (captured in this model in a genetic profile or as Clinical Modifiers).

Goals includes reason(s) for seeking care (reasons for encounter), expressed goals, priorities and preferences for care, illness burden, and functional status, representing the point of view of the person experiencing care. These elements capture a person's state data that can and will change with time and that should guide clinicians in providing person-centered care.

Clinical Modifiers includes previous clinical, behavioral, or social events that are no longer active problems but that could or should affect care for current or new problems. Examples might include major medical events (hysterectomy, myocardial infarction, history of cerebrovascular accident); emotional trauma, such as an assault; and secondary or tertiary prevention issues, such as local environmental problems. Clinical Modifiers enables the systematic capture of unstructured but important clinical information clinicians sometimes enter in sticky note fields in current EHRs. 
Actions includes the range of actions taken or decisions made during the course of care: engagement of family members in care, engaged health care team members, linkages or referrals to community resources, laboratory or ancillary service use, referral decisions, procedures performed, pharmacy orders, exception or error reporting, and disposition (follow-up plans). The Actions object captures the process of care for problems over time.

The model contains 2 core structural components. An episode structure addresses the linkage of actions to problems, enabling clinical data to be placed in the context of time and earlier actions. In a model that adheres to the episode structure, each problem has a history that traces encounters and actions taken to address the problem. Without this structure, clinical data lose much of their meaning and its validity. One important advantage of this feature is that it enables the calculation of specific disease probabilities for presenting symptoms, as well as the proportion of symptoms that resolve without diagnosis. Data exchange protocols are necessary to standardize inputs and outputs of interoperable clinical data by patients, clinicians, and automated data feeds. The clinical, social, family, and community data required to provide high-quality patient-centered care will increasingly come from patients and their personal devices, from community sources, and from automated data feeds from multiple sources. Examples include direct patient entry of requests for services, import of data obtained outside the practice (ranging from cardiac catheterization results to glucosemonitoring data posted by mobile devices, to automated posts of data from sensors embedded in smartphones, to soil contaminant levels in a census tract), and structured export of data to support clinical care transitions.

This model includes all data elements from the Common Clinical Data Set described by the $\mathrm{ONC}_{1}{ }^{38}$ and it complements the NCVHS communitypopulation health data model shown in Figure 1. The 5 core objects were conceived to capture and codify key social determinants of health (in Persons and Clinical Modifiers) and the family and community context in which personal doctoring occurs (in Persons, Goals, and Clinical Modifiers). Several of these data elements are already specified in the NCVHS model, most clearly seen under the category headings of social attributes, economic resources, collective lifestyles, and cultural context.

Linked together, the 2 models can provide a comprehensive, community-oriented, primary care data model that integrates social, environmental, and clinical information at the personal, community, and population level:

$C C D=$ Continuity of Care Document; HEDIS = Healthcare Effectiveness Data and Information Set; HL7 = Health Level Seven International; $\mathrm{XML}=$ Extensible Markup Language; $\mathrm{TBD}=$ to be determined. 
Figure 3 illustrates its potential utility in everyday clinical practice. This linkage can provide a roadmap to guide the integration of population health and primary care data necessary to assess the value of primary care to the overall health care enterprise.

\section{Some Distinguishing Primary Care Model Features That Need Immediate Attention}

Much work remains to be done to identify the standard content that can bring this model to life; some content is already available but deeply buried in enterprise EHR software. Work is also needed to reduce and realign the technology overhead, current EHR platforms require clinicians to expend considerable effort to collect and enter highly granular clinical and billing data that are minimally useful in supporting patientcentered primary care. ${ }^{36,39}$ It seems clear that disruptive innovation will be required to re-engineer the primary care health IT infrastructure.

The first challenge is developing the new core content specified in the data model. Prior work to apply the biopsychosocial model in clinical care, current applied theories of heath behavior, and advances in genomics research can collectively guide efforts to identify the core data elements to include in Persons. Further research is needed to identify and operationalize core social determinant standards from the NCVHS model, then partner with patients and community stakeholders to find acceptable ways to collect and integrate these data. The core content for Goals can build upon current efforts to collect and codify patient goals and preferences and reasons for encounter, using existing instruments to measure functional status and illness burden. Although the concept

\section{Clinical Situation:} determined. of Clinical Modifiers as structured and codified sticky notes is appealing, work to determine what events to include and where to fit in primary prevention and preventive actions remains to be done. The Wonca International Classification Committee is active in this area of work ${ }^{40}$ but no consensus has yet emerged.

The second challenge is to optimize the data model content found in the current generation of EHRs. EHR problem lists are generally unstructured and uncontrolled; they include acute and chronic

\section{Figure 3. Example of potential utility of primary care data model in clinical care coordination.}

Jane Smith is 17 years old, has asthma, is a single mother of a 4 month-old baby, and is living with her single mother while she finishes high school. This family lives in an old house in a wet climate. Jane has nightly asthma symptoms that disrupt sleep, with sleep further disrupted by her baby's sleeping problems and feeding schedule. Jane is not using prescribed corticosteroids because she is afraid they will appear in her breast milk and harm her baby. She is using a rescue inhaler at times during night, making sleep still more difficult. School performance is declining, and she is considering dropping out. She has not visited her school-based clinic. She was seen at her PCMH practice for her prenatal and postpartum visits but not for asthma, as well-child visits are a higher priority for her limited time.

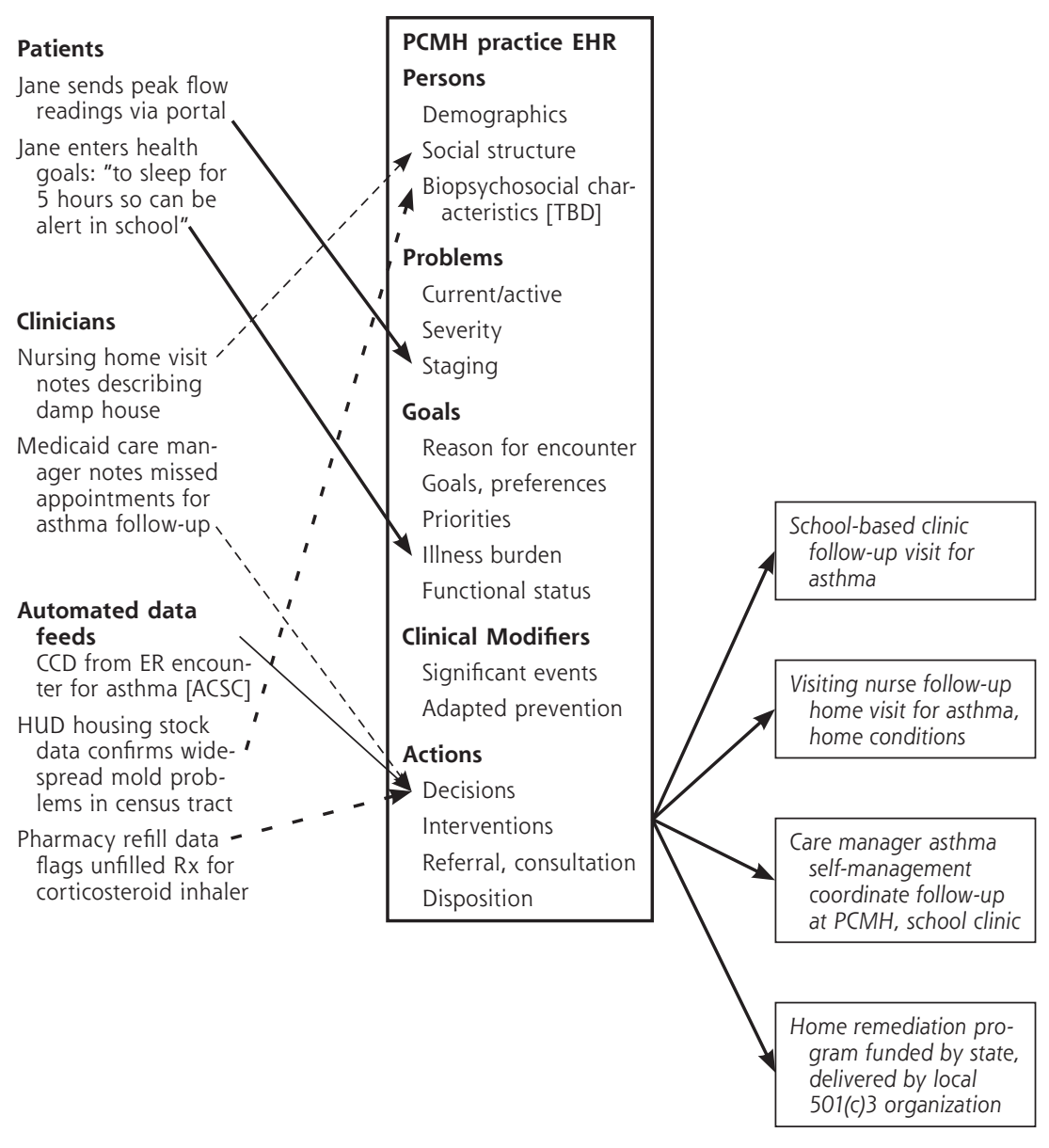

$\mathrm{ACSC}=$ ambulatory care sensitive conditions; $\mathrm{CCD}=$ Continuity of Care Document; $\mathrm{ER}=$ emergency department; $\mathrm{HUD}=$ Housing and Urban Development; $\mathrm{PCMH}=$ primary care medical home; $\mathrm{Rx}=$ prescription; $\mathrm{TBD}=$ to be 
symptoms and diagnoses, duplicated or overlapping problem and disease labels, risk factors, and some clinical modifiers. Most problem list entries are not referenced to a structured terminology or classification that can facilitate data extraction, display, and analysis at the point of care. Active social, family, or community problems that affect care are rarely recorded. Actions are recorded in detail-particularly immunizations, procedures, prescriptions, laboratory tests, and other items (supplies) that can be billed for-but are not uniformly linked to problems or to standard terminologies. Restructuring this content and structure will require considerable effort.

The third and most difficult challenge will come with re-engineering health IT infrastructure to enable routine collection of core content that aligns with the thought-flow and workflow of primary care while at the same time reducing the technology overhead of the primary care practice. This can be achieved through an interactive record that accepts input directly from persons (patients), clinicians, and automated data exchange (Figure 2). It will require a major human-factors engineering effort to learn how to assemble data from direct person entry, ubiquitous personal devices and sensors, and automated feeds from medical databases, then to sort and filter those data in ways that support the patient-focused, family- and community-contextualized clinical work of primary care. Technical standards for coding and transmission of novel data elements must be created. Although decisions must be made about standards for episode-based data entry and retrieval to operationalize the element of time in the EHR data structure, several current examples of how this might be approached can be found from clinical information systems implemented in other countries. ${ }^{41-44}$

\section{A Way Forward}

The 2007 Harmonizing Primary Care Clinical Classification and Data Standards conference, convened by The Robert Graham Center and Agency for Healthcare Research and Quality, brought together multiple stakeholders to create a strategy map to support primary care health IT transformation. ${ }^{31}$ The action items from that map provide a good starting point for a renewed effort, including the following steps.

1. Create a collaborative primary care data standards working group to complete development of the data model and coordinate its testing and dissemination. This expert group would be commissioned to review and revise the current draft data model while being attentive to new ways of collecting and novel ways of synthesizing data, and then work with content area experts to decide upon and/or develop core data elements and measurement options.
2. Vet the data model with stakeholders, including primary care organizations, federal agencies (eg, NCVHS and $\mathrm{ONC}$ ), national organizations (eg, National Committee for Quality Assurance (NCQA), National Quality Forum (NQF), and Patient-Centered Primary Care Collaborative (PCPCC), as well as EHR vendors.

3. Create the business case for the data model across the full range of stakeholders, including primary care practices, vendors, health care systems, and a general public increasingly engaged in developing a high-value health care system and a healthier population.

4. Develop partnerships with one or a few health IT vendors willing to create and evaluate IT products that integrate the content and structural features of the data model.

5. Test the data model with demonstration projects in a variety of clinical settings, followed by broader community-based trials. Large-scale trials could occur through alliances with payers, purchasers, and other organizations to incorporate some or all data model components into clinical demonstrations or ongoing initiatives (eg, state innovation model demonstration projects). The model will need testing in several settings to see whether it supports multiple use cases. 6. Create tools that can enable users (patients, clinicians, practices, and communities) to work directly with their own data at the point of care and where they live. This could be accomplished through partnerships with existing database management vendors or professional organizations (eg, the American Board of Family Medicine's TRADEMaRQ [Trial of Aggregate Data Exchange for Maintenance of Certification and Raising Quality] and DAIQUERI [Data Abstraction and Intelligence Quality Engine for Research and Improvement] initiatives ${ }^{45}$ ), or through new data stewardship infrastructures as illuminated by NCVHS. ${ }^{24}$

\section{CONCLUSION}

It is a propitious moment to act in behalf of a proper data model for primary care. It is an ambitious, intimidating undertaking that is relevant, targeted, and timely. The Proceedings of the 2007 Harmonizing Primary Care Data Standards conference highlight the continued importance of this issue to primary care:

The key decision made by attendees was that it was very important to act now to develop and promote the data model for personal doctoring in the medical home to support the transformations of health IT and personalized health care that are already underway. ${ }^{31}$

In the recently released Nationwide Interoperability Roadmap report, ONC calls for a set of standards that allow sharing of health information for small 
(individual patient), big (population-level), and long data (wrapping around the individual and telling their health story over time).$^{38}$ A primary care data model is an essential step in building national capacity to collect small data, to make it long, and to link it to big data. This will greatly enhance our efforts to improve the health of individuals and communities.

Key words: primary health care; community health services; health information technology; outcome and process assessment (health care); electronic health records; medical informatics; classification; population health; health data standards

To read or post commentaries in response to this article, see it online at http://www.annfammed.org/content/13/4/303.

Submitted May 26, 2015; submitted, revised, May 26, 2015; accepted May 27, 2015.

\section{References}

1. Donaldson MS, Yordy KD, Lohr KW, Vanselow NA, eds. Institute of Medicine. Primary Care: America's Health in a New Era. Washington, DC: National Academy Press; 1996.

2. Starfield B, Shi L, Macinko J. Contribution of primary care to health systems and health. Milbank Q. 2005;83(3):457-502.

3. Phillips RL Jr, Bazemore AW. Primary care and why it matters for U.S. health system reform. Health Aff (Millwood). 2010;29(5):806-810.

4. Shi L. The impact of primary care: a focused review. Scientifica. 2012;2012:1-22

5. Committee of Quality of Health Care in America. Institute of Medicine. Crossing the Quality Chasm: A New Health System for the 21st Century. Washington, DC: National Academy Press; 2001.

6. Woolf SH, Aron L, eds. Institute of Medicine. US Health in International Perspective: Shorter Lives, Poorer Health. Washington, DC: The National Academies Press; 2015.

7. Stevens R. American Medicine and the Public Interest: A History of Specialization. Berkeley, California: University of California Press; 1998.

8. Stange KC. The Annals of Family Medicine editorial series on integrative approaches to promoting health and personalized, high-value health care. Ann Fam Med. 2009-2010;7:100-103,198-204,293299,387-395,484-487;8:4-10,100-107.

9. White KL, Williams TF, Greenberg BG. The ecology of medical care. N Engl J Med. 1961;265:885-892.

10. Green LA, Fryer GE Jr, Yawn BP, Lanier D, Dovey SM. The ecology of medical care revisited. N Engl J Med. 2001;344(26):2021-2025.

11. Bodenheimer T, Ghorob A, Willard-Grace R, Grumbach K. The 10 building blocks of high-performing primary care. Ann Fam Med. 2014;12(2):166-171.

12. Phillips RL Jr, Pugno PA, Saultz JW, et al. Health is primary: family medicine for America's health. Ann Fam Med. 2014;12(12)(Suppl 1): S1-S12.

13. Young RA, DeVoe JE. Who will have health insurance in the future? An updated projection. Ann Fam Med. 2012;10(2):156-162.

14. National Commission on Community Health Services. Health is a Community Affair. Cambridge, Massachusetts: Harvard University Press; 1966.

15. Folsom Group. Communities of solution: the Folsom Report revisited. Ann Fam Med. 2012;10(3):250-260.

16. Committee on crossing the quality chasm. Institute of Medicine. Adaptation to Mental Health and Addictive Disorders. Washington, DC: The National Academies Press; 2005.
17. O'Connell ME, Boat T, Warner KE, eds. Institute of Medicine. Preventing Mental, Emotional, and Behavioral Disorders Among Young People: Progress and Possibilities. Washington, DC: The National Academies Press; 2009.

18. Committee on integrating primary care and public health. Institute of Medicine. Primary Care and Public Health: Exploring Integration to Improve Population Health. Washington, DC: The National Academies Press; 2012.

19. Olsen L, Aisner D, McGinnis JM. Institute of Medicine. The Learning Healthcare System: Workshop summary (IOM Roundtable on EvidenceBased Medicine). Washington, DC: The National Academies Press; 2007.

20. Clinical and Translational Science Awards consortium. CTSA Community Engagement Key Function Committee Task Force on the Principles of Community Engagement. 2nd ed. Atlanta, GA: Agency for Toxic Substances and Disease Registry, 2011.

21. Grossman C, Powers B, Sanders J. Rapporteurs. Roundtable on value and science-driven health care - Digital Data Improvement Priorities for Continuous Learning in health and healthcare. Institute of Medicine. The National Academies Press. Washington, DC. 2012.

22. Alper J, Sanders J, Sunders R. Rapporteurs. Roundtable on Value and Science-Driven health Care -Core Measurement Needs for Better Care, Better health, and Lower Costs. Counting What Counts. Institute of Medicine. The National Academies Press. Washington, DC. 2013.

23. Committee on Core Metrics for Better Health at Lower Cost. Institute of Medicine. Vital Signs: Core Metrics for Health and Health Care Progress. Washington, DC: The National Academies Press; 2015.

24. Friedman D. Massachusetts Department of Public Health, National Committee on Health and Vital Statistics. Shaping a Health Statistics Vision for the 21st Century. Presented at 2002 NCHS Data Users Conference; July 16, 2002. http://www.ncvhs.hhs.gov/wp-content/ uploads/2014/05/111213chip.pdf. Accessed Apr 10, 2015.

25. Kanaan SB; National Committee on Vital and Health Statistics. The community as a learning system: using local data to improve local health. http://www.ncvhs.hhs.gov/wp-content/ uploads/2014/05/111213chip.pdf. Published Dec 2011.

26. Data for health advisory committee. Data for health: learning what works. Princeton, NJ: Robert Wood Johnson Foundation; 2015. http://www.rwjf.org/content/dam/farm/reports/reports/2015/ rwjf418628. Accessed April 10, 2015.

27. The Office of the National Coordinator for Health Information Technology. Connecting health and care for the nation: a 10-Year vision to achieve an interoperable health IT infrastructure. Health IT Web site. http://healthit.gov/sites/default/files/ONC10year/nteroperabilityConceptPaper.pdf. Published Jun 5, 2014. Accessed Apr 10, 2015.

28. Circle Square, Inc. HIT trends. Karmadata Web site. https://www. karmadata.com/Data/Pdf?file $=$ HITTrendsJune2014.pdf. Published June 2014. Accessed Apr 10, 2015.

29. American Board of Medical Specialties. Better patient care is built on higher standards. http://www.abms.org/about-abms/. Accessed Apr 10, 2015.

30. Wachter RM. Why health care tech is still so bad. New York Times. http://www.nytimes.com/2015/03/22/opinion/sunday/why-healthcare-tech-is-still-so-bad.html?_r=0. Published Mar 21, 2015. Accessed Apr 10, 2015.

31. Phillips RL Jr, Klinkman M, Green LA. Conference Report: Harmonizing Primary Care Clinical Classification and Data Standards. http:// www.graham-center.org/content/dam/rgc/documents/publicationsreports/monographs-books/harmonizing-primary-care.pdf. Published 2007. Accessed Apr 10, 2015.

32. Data model. Wikipedia Web site. http://en.wikipedia.org/wiki/ Data_model. Accessed Apr 17, 2015.

33. Haughey T. The conceptual data model. ERwin Web site. http:// erwin.com/community/expert-blogs/the-conceptual-data-model. Published Mar 4, 2011. Accessed Apr 21, 2015. 
34. Stange KC. A science of connectedness. Ann Fam Med. 2009;7(5): 387-395.

35. Krist AH, Beasley JW, Crosson JC, et al. Electronic health record functionality needed to better support primary care. J Am Med Inform Assoc. 2014;21(5):764-771.

36. European Committee for Standardization (CEN). Health informatics. Classification of purposes for processing personal health information. CEN/TC 251. http://standards.cen.eu/dyn/www/ $f ? p=204: 110: 0: \cdots:$ FSP_PROJECT,FSP_ORG_ID:33991,6232\&cs = 15A5 COA18F36D40F6B2E4E4FFF3CF6650. Published 2013. Accessed Apr 21, 2015.

37. Klinkman MS. Classifications, terminologies, and their use in primary care health information technology: towards a primary care data model. In: Phillips RL Jr, Klinkman M, Green LA, eds. Conference Report: Harmonizing Primary Care Clinical Classification and Data Standards. Washington, DC: Robert Graham Center;2007:55-77.

38. The Office of the National Coordinator for Health Information Technology. Connecting health and care for the nation: a shared nationwide interoperability roadmap, draft version 1.0. Health IT Web site. http://www.healthit.gov/sites/default/files/nationwideinteroperability-roadmap-draft-version-1.0.pdf. Published Jan 2015. Accessed Apr 27, 2015.

39. O'Malley AS, Draper K, Gourevitch R, Cross DA, Scholle SH. Electronic health records and support for primary care teamwork. J Am Med Inform Assoc. 2015;22(2):426-434.
40. Wonca International Classification Committee. 2014 annual meeting documents. Primary Health Care Classification Consortium Web site. http://www.ph3c.org/4daction/w3_CatVisu/en/lisbon-meeting-2014docs-slides-and-countries-annual-reports.html?wDocID $=351$. Published Aug 25, 2014. Updated Jan 21, 2015. Accessed May 2, 2015.

41. Kounalakis DK, Lionis C, Okkes I, Lamberts H. Developing an appropriate EPR system for the Greek primary care setting. J Med Syst. 2003;27(3):239-246.

42. Laux G, Kuehlein T, Rosemann T, Szecsenyi J. Co- and multimorbidity patterns in primary care based on episodes of care: results from the German CONTENT project. BMC Health Serv Res. 2008;8:14.

43. Soler JK, Okkes I, Oskam S, et al. The interpretation of the reasons for encounter 'cough' and 'sadness' in four international family medicine populations. Inform Prim Care. 2012;20(1):25-39.

44. Rizza A, Kaplan V, Senn O, Rosemann T, Bhend H, Tandjung R; FIRE study group. Age- and gender-related prevalence of multimorbidity in primary care: the Swiss FIRE project. BMC Fam Pract. 2012;13:113-119.

45. DeMaio S. Simplifying MOC for Family Physicians: the TRADEMaRQ study. NEJM Knowledge+ Web site. http://knowledgeplus.nejm. org/simplifying-moc-for-family-physicians-the-trademarq-study/. Published Mar 26, 2015. Accessed Apr 27,2015.

\section{CORRECTIONS}

Ann Fam Med 2015;13:311. doi: 10.1370/afm.1835.

Phillips RL, Brundgardt S, Lesko SE, et al. The future role of the family physician in the United States: a rigorous exercise in definition. Ann Fam Med. 2014;12(3):250-255.

In this paper, one of the author's names is misspelled Brundgardt. The correct spelling is Brungardt. The article was corrected online.

Ann Fam Med 2015;13:311. doi: 10.1370/afm.1834.

Bazemore A, Petterson S, Peterson LE, Phillips RL. More comprehensive care among family physicians is associated with lower costs and fewer hospitalizations. Ann Fam Med. 2015;13(3):206-213.

In the print version of this paper, it states that The Robert Graham Center received support for this study from the American Board of Family Physicians. The correct name for the organization is the American Board of Family Medicine. The article was corrected online.

Ann Fam Med 2015;13:311. doi: 10.1370/afm.1836.

Cecil E, Bottle A, Sharland M, Saxena S. Impact of UK primary care policy reforms on short-stay unplanned hospital admissions for children with primary care-sensitive conditions. Ann Fam Med. 2015;13(3):214-220.

In the Results section of this article, the reference to Table 2 of Supplemental Appendix 2 and Table 3 of Supplemental Appendix 2 are extraneous and in error. There are no tables in Supplemental Appendix 2. The article was corrected online.

Ann Fam Med 2015;13:311. doi: 10.1370/afm.1833.

Heleno B, Siersma VD, Brodersen J. Diagnostic invasiveness and psychosocial consequences of false-positive mammography. Ann Fam Med. 2015;13(3):242-249.

In the legends for Figures 2 and 3 of this paper the author reports an error. In both figures, the dashed line with diamonds should be "Normal" and the dotted line with crosses should be "Breast cancer." The article was corrected online. 